\section{Simple Endoscopic Treatment of a Granular-Cell Tumor of the Esophagus}

Granular-cell tumors (GTCs) are rare neoplasms characterized by large polygonal cells containing numerous eosinophilic granules. No general consensus exists about the treatment of this lesion.

A 53-year-old woman underwent an endoscopic resection of a sessile polypoid lesion in the esophagus at our hospital. The polypoid lesion was located approximately $25-30 \mathrm{~cm}$ from the incisor teeth, and a soft consistency was noted when it was touched with biopsy forceps; it measured approximately $15-20 \mathrm{~mm}$ in diameter, and presented a villous appearance surrounded by normal mucosa. The histological findings in the biopsy specimens were consistent with benign GCT. In view of the nature and size of lesion, we decided to use endoscopic treatment by debulking with a biopsy forceps to remove the visible neoplasm. This procedure was performed on 10 June 1990. Two weeks later, a histological examination still showed the presence of tumor cells. We therefore applied endoscopic injections of polidocanol $1 \%(5 \mathrm{ml})$ to achieve necrosis of the submucosal neoplastic cells. When $1 \%$ methylene blue was added to the polidocanol, we observed intramural and intratumoral diffusion of the dye, thus avoiding the induction of a large ulceration, with consequent prevention of scarring stenosis. No complication occurred during the procedure. Endoscopic examinations of the esophagus with biopsies eight, 20,36, and 48 
months later did not show any residual neoplastic lesion or scarring stenosis.

The treatment of choice for esophageal GTC is still a matter of debate. The traditional procedure was represented by surgical local excision, but new therapeutic options, including laser (1), diathermy loop (2), and multiple biopsies (3) have recently been proposed. Laser treatment has been carried out successfully without adverse effects, but it is an expensive technique that is not always available (1). By contrast, excision by biopsy forceps is cheaper and more readily available than the laser technique, although it is not free of risk due to imperfect removal (3). The diathermy loop is an effective procedure, but it is potentially dangerous due to the submucosal location of the tumors and the consequent high risk of perforation (2). Intratumoral polidocanol injections have been used for palliative treatment of gastrointestinal tumors $(4,5)$. Our technique allows multiple biopsies, and avoids imperfect removal of the submucosal neoplasm by using polidocanol injection. In conclusion, multiple biopsies and submucosal injection of polidocanol could represent an effective, safe, and cheap option for the treatment of small esophageal GCTs.

M. R. Maccarini, G. Michieletti, I. Tampieri, O. Triossi, E. Bertinelli, T. Casetti

Gastroenterology and Digestive Endoscopy Service, S. Maria delle Croci Hospital, Ravenna, Italy

\section{References}

1. Choi PM, Scheider L. Endoscopic Nd:YAG laser treatment of granular cell tumor of the esophagus. Gastrointest Endosc 1990; 36: 144-6.

2. Cohle SD, Mackechnie JC, Truong L, et al. Granular cell tumor of the esophagus by endoscopic injection of dehydrated alcohol. Am J Gastroenterol 1990; 85: 1507-11.

3. Tada S, Iida M, Miyagara T, et al. Granular cell tumor of the esophagus: endoscopic ultrasonographie demonstration and endoscopic removal. Am J Gastroenterol 1992; 87: 659-61.

4. Soehendra N, Grimm H, Schrein W. Endoskopische Injektionsbehandlung bei benigne und maligne Oesophagusstenosen. Dtsch Med Wochenschr 1984; 109: 659-61.

5. Marini E, Frigo F, Cavarzare L, et al. Palliative treatment of carcinoma of the rectum by endoscopic injection of polidocanol. Endoscopy 1990; 22: 171-3.

Corresponding Author

T. Casetti, M.D.

Servizio di Gastroenterologia ed Endoscopia Digestiva Ospedale S. Maria delle Croci

Via le Randi 5

48100 Ravenna

Italy

Fax: +39-544-409325 